\title{
Los actores de la corrupción: políticos de negocios en Italia
}

\section{Donatella della Porta*}

En la corrupción política se encuentran e intercambian recursos dos actores: uno público y otro privado. Para el estudio del funcionamiento de los regímenes democráticos es de la máxima importancia comprender las condiciones que permiten a los actores públicos abandonar sus obligaciones implicándose en transacciones ilícitas. Las principales teorías sobre la corrupción proporcionan algunos puntos de partida para abordar este tema. LoS estudios sociológicos y políticos han separado las causas del fenómen $0^{1}$ en dos niveles: en primer lugar, el macrosistema en el que se produce la corrupción, y en segundo, los individuos implicados en ella. Así, se pueden distinguir dos líneas principales de aproximación al fenómeno de la corrupción; el primero parte de asumir la funcionalidad del sistema, el segundo se basa en la racionalidad individual.

El punto de partida de la aproximación funcionalista es una crítica hacia los «moralistas» que consideran la corrupción como un fenómeno patológico, un obstáculo para el desarrollo económico o una amenaza para la política legítima, debida al acceso de personas sin escrúpulos a puestos de poder. Los funcionalistas, interesados sobre todo en el estudio de los sistemas políticos y económicos de los países en desarrollo, han afirmado que la corrupción tenía sus raíces en el propio sistema, intentando explicar históricamente la aparición periódica de formas de mala administración, con utilización privada o apropiación de recursos públicos. Más que por una cultura política en concreto, el surgimiento del fenomeno estaría determinado por el grado de desarrollo político o económico. La hipótesis principal es que la corrupción es una «disfunción funcional», por la cual se reemplazan unas normas viejas y obsoletas por otras nuevas que se adaptan a los cambios que se producen en otros subsistemas. Una vez cumplidas sus funciones políticas y económicas, desaparecería. En lo que respecta a las primeras, de las political machines de las gran- des ciudades americanas en el decenio de 1920, se dijo que habían contribuido a la integración de nuevos grupos de población ofreciendo su mediación frente a un Estado distante e impersonal 2. Más aún, se llegó a pensar que la corrupción tenía un efecto positivo en algunas fases del ciclo económico permitiendo superar obstáculos burocráticos, estimulando inversiones y fomentando la creación de empresas. D esde el punto de vista de las motivaciones individuales, a las que estos estudios no prestan demasiada atención, se podría afirmar que son sobretodo las condiciones de tensión del sistema las que impul san a los individuos a desviarse de las normas.

La aproximación funcionalista dominante en los decenios de 1950 y 1960 fue criticada de manera radical en el decenio siguiente. Se acusó a los funcionalistas de fundamentar su teoría de la corrupción política sobre estudios superficiales, racionalizaciones imprudentes y programas de intervención formulados con vaguedad (TILMAN, 1968, 437). Sobre todo se rechazaron las dos hipótesis, tanto la de que la corrupción tenía una función positiva en el sistema económico y político como la de que desaparecería cuando ya no tuviera utilidad. Estas ideas han sido abandonadas por la más reciente political economy approach que ha adoptado en su lugar una perspectiva del individualismo me todológico: la corrupción política es considerada como el resultado de un cálculo racional de costes y beneficios ${ }^{3}$. Esta aproximación coincide con diversos estudios que comparten la idea de que la corrupción procede de un cálculo por parte de los individuos. Éstos son considerados como seres calculadores que tratan de asegurar sus propios intereses en un mundo de escasos recursos. Más concretamente se cree que a los políticos y a los burócratas les interesa tanto el dinero como el poder y por eso tratan de lograr un punto de equilibrio entre los comportamientos adecuados para obtener dinero para ellos, y los necesarios para ser 
reelegidos o para conservar sus puestos de trabajo. Partiendo de un comportamiento individual dominado por intereses materiales privados, estos estudios han descubierto al gunas variables (de modo deductivo en la mayoría de los casos) que pueden influir en los cálculos individuales de si es o no ventajoso participar en una transacción corrupta. La political economy approach tiene el mérito, si se compara con la aproximación funcionalista, de reflejar detalladamente las variables (sobre todo las de tipo organizativo) que influyen más directamente en la decisión de participar en la corrupción. Pero también esta aproximación ha sido criticada por la parcialidad de sus principios. Sus hipótesis analíticas de natural eza económica se expresan por medio de modelos lógico-deductivos más o menos formalizados que parten del postulado de que los individuos se comportan de manera racional y se orientan a sacar el máximo provecho. Aunque muy «elegantes» en su formulación, estos modelos analíticos tienen serias dificultades para considerar adecuadamente la diversidad de las motivaciones individuales. Aunque los political economists mencionan una variable llamada «coste moral», en realidad no la tienen en cuenta a la hora de decir cuáles son las características individuales de propensión a la corrupción, considerando a menudo el coste moral de participar en actividades ilícitas como una constante (PIzzorno, 1992, 15 y 43).

Así pues, lo que les falta a ambas aproximaciones es un análisis de la interacción entre los aspectos micro (individuales) y los macro (estructurales) del fenómeno; un análisis que clarifique el paso de las condiciones estructurales previas al comportamiento individual. Con esta aportación trato de sugerir que, para comprender el nacimiento y la extensión de la corrupción, es necesario observar las características de los funcionarios que caen en las prácticas corruptas. Como observó Alessandro Pizzo Rno, la intermediación política en democracia debería orientarse, como norma, a descubrir las necesidades y deseos de los ciudadanos y proceder a una selección, a una formulación de objetivos a largo, medio y corto plazo, y a una explicación de por qué se toma una medida en concreto en lugar de otra. La carrera de un político estará motivada fundamentalmente por la búsqueda del reconocimiento público y las cualidades requeridas serán la capacidad de síntesis ideológica y la capacidad oratoria, ambas necesarias para las tareas que acabamos de mencionar. Cuando la corrupción contamina el sistema, las funciones desempeñadas, las capacidades específicas activadas, y las motivaciones de la carrera, se transforman. Si en la actividad de la intermediación política tradicional - entendida como descubrir, aunar y representar intereses- , la cualidad más necesaria es «la capacidad de generalizar las demandas particulares en términos ideológicos o programáticos, de manera que obtenga el mayor consenso posible, dentro de ciertos límites» (PIzzo Rn 0, 1992, 22), cuando se extiende la corrupción se necesitan diferentes tipos de capacidades. En estas situaciones, se difunde un tipo especial de funcionario público: el político de negocios aś llamado porque «combina la media- ción con los negocios (legales o ilegales), y, en general, la participación personal en actividades económicas, con la mediación política en el sentido tradicional» (PIzzorno, 1992, 24) 4.

En lo que sigue a continuación trataré de reconstruir las condiciones que hacen posible el surgimiento de los «políticos de negocios", los recursos que estos políticos invierten en sus carreras y las funciones que desempeñan en las transacciones corruptas. La exposición se basa en los resultados de un estudio sobre la corrupción política en Italia y hace uso de documentos procedentes de cuarenta procedimientos por delitos contra la administración pública, de informes de comisiones parlamentarias que tratan temas relacionados con la corrupción, de peticiones de autorización para proceder contra miembros del Parlamento (suplicatorios) durante la penúltima legislatura, así como dela prensa diaria y de entrevistas con observadores bien informados ${ }^{5}$.

\section{La crisis de los partidos de masas y el nacimiento de los políticos de negocios}

Los estudios clásicos sobre el poder local han descubierto las condiciones previas para el descenso de las cualidades morales de la clase política en el acceso al poder de al gunos grupos especiales. Robert DaHL (1961), en su famoso estudio sobre N ew Haven, tomando como base el origen social de los funcionarios que ocupaban puestos de poder institucional, señaló cuatro fases en el paso de la oligarquía al pluralismo, es decir, de la concentración a la dispersión de los recursos políticos más importantes. La primera se caracterizaba por el predominio de los patricios, una clase dirigente que acumulaba todos los resortes del poder (riqueza, instrucción y status social) y que gozaba de un alto grado de legitimidad. Con la extensión del sufragio y del voto secreto, el poder de los patricios disminuyó, y aumentó el de los empresarios, ricos pero faltos de prestigio social e instrucción. A pesar de su popularidad (debida a su capacidad de identificarse con el sistema de valores dominante), los empresarios eran muy pocos. Con el auge de la industrialización y la consiguiente inmigración de nuevos grupos étnicos, se abrió el camino a los ex-plebeyos, que no tenían ni riqueza ni instrución, pero sí la capacidad de crearse adeptos entre los nuevos inmigrantes.

La llegada de los ex-plebeyos dio lugar a una transformación del ethos político:

Los líderes políticos y sus seguidores empezaron a utilizar el sistema político con el fin de eliminar los hándicaps propios de los grupos étnicos más que para mejorar las 
dificultades derivadas de la distribución de recursos por parte del mismo orden socio económico existente (D AHL, 1961, 33).

Fue en esta fase cuando surgió la corrupción porque los nue vos dirigentes políticos, con frecuencia procedentes ellos mismos de grupos étnicos discriminados, empezaron a ofrecer protección a cambio de apoyo electoral:

Como los dirigentes políticos esperaban extender su propia influencia gracias a los votos de los grupos étnicos, ayudaron a los inmigrantes a superar su inicial falta de poder político, haciéndoles entrar en política. Aunque les faltaba todo lo demás, los grupos étnicos eran fuertes porque eran muchos. Así que los políticos tomaron la iniciativa; facilitaron a los inmigrantes el convertirse en ciudadanos, animando a los grupos étnicosa registrarseen el censo, los inscribieron en los partidos y les ayudaron a superar los innumerables problemas específicos derivados de su pobre za, del hecho de ser extranjeros, y de su bajo status social. Para obtener y mantener losvotos, los líderespolíticos lesrecompensaron con empleos públicos (D AHL, 1961, 34).

Sin embargo, según D AHL, la integración de estos grupos étnicos en la comunidad disminuyó el poder de los ex-plebeyos.

0 tros estudiosos del poder local relacionan el descenso de la calidad moral de la clase política con los orígenes sociales de manera más explícita que D AHL, explicando una especie de ethos de clase. Según estas hipótesis, mientras que la clase media considera la política como un servicio a la comunidad, valorando las virtudes públicas como la honestidad, la eficiencia y la imparcialidad, las clases bajas prefieren el clientelismo político y la corrupción de donde obtienen una protección especial que les es necesaria. Especialmente Edward BAN FIELD y James Q. W ILSON han sostenido que:

... El ideal de la clase media considera la política local como una búsqueda en colaboración de las implicaciones concretas de un interés público más o menos objetivo, y de un interés de la comunidad 'como conjunto'. La lógica del ideal de la clase media requiere que la autoridad sea ejercida por 'los mejor cualificados', es decir, por técnicos experimentados y hombres de Estado, no por 'políticos'. La lógica del ideal de la clase media implica también ciertos ajustes institucionales (ausencia de partidismo, elecciones generales, gestión del municipio, planeamiento y organización del area metropolitana); un respeto especial hacia las virtudes públicas de honradez, eficiencia e imparcialidad; y una disposición a fomentar el consumo de 'productos públicos' como escuelas, parques, museos, bibliotecas y, por extensión, renovación de espacios urbanos... La política a la antigua usanza del jefe y la máquina está y seguirá estando, sin duda, claramente ligada a las clases bajas» (BANFIELD y W ILSON, 1967, 330).
El caso italiano respalda sólo parcialmente estas hipótesis de sarrolladas a partir de los estudios realizados sobre los Estados Unidos de América. En especial los políticos de negocios parecen surgir en las épocas de transformación de los partidos políticos, sobre todo en las crisis de los partidos de masas. El auge de la corrupción no pareceestar relacionado con la sustitución de una clase política burguesa por otra formada por las clases bajas, sino más bien con la disminución de la influencia de una clase política (a menudo de orígenes obreros) con fuertes motivaciones ideológicas y la entrada en política de un grupo (procedente de las clases medias) que considera que la política no es más que un negocio como otro cualquiera. Esto se hace más evidente, sobre todo, al reconstruir la historia local del partido político más implicado en los recientes escándalos: el PSI [Partido Socialista Italiano].

En las dos federaciones locales estudiadas, Savona, en el norte de Italia y Florencia en el centro, la transformacion del partido que dará lugar a que se infiltre en él una clase de políticos con escaso sentido de la moralidad pública, ya había empezado en los años inmediatos a la posguerra. El gradual abandono del partido por parte de la clase obrera se aceleró bruscamente cuando el ala izquierda de dicho partido abandonó éste para fundar el PSIUP [Partido Socialista Italiano de Unidad Proletaria] en 1964. En la entrevista a un militante de aquellos años se explican las tran sformaciones sociales y de tipo organizativo del partido:

La historia del PSI savonés... tiene dos etapas diferentes. En primer lugar, empezando desde 1943, la época he roica de la clandestinidad y los años de la post-Resistencia, muchos militantes del partido proceden de las filas de la Resistencia... En esa época los militantes procedían de grupos sociales muy dispares: hay muchos profesionales, abogados antifascistas, por ejemplo; también hay muchos obreros que más tarde abandonarán el partido en masa con la escisión del PSIUP y con la transformación del partido. Por entonces el PSI tenía un fuerte núcleo de trabajadores ferroviarios, de estudiantes, de trabajadores de la Italsider y de otras grandes fábricas de Savona (que era una zona fuertemente industrializada). Tanto es así que, en las primeras elecciones después de la guerra, el PSI tuvo más votos que el PCI (Partito Comunista Italiano). D espués vino una etapa intermedia en la que todavía se dejaba sentir la influencia de la Resistencia. Sin embargo, después se produjo una auténtica ruptura generacional (EntrevistaSV 6) ${ }^{6}$.

En Florencia, al igual que en Savona, la escisión del PSIUP dio lugar a una reducción del número de miembros en las secciones del partido, debilitó los contactos con el movimiento sindical y ocasionó pérdidas electorales significativas. Según un dirigente del partido:

La rupturaen el PSI deFlorenciaocurrió en 1964, cuando lo abandonaron los sindicalistas. De hecho, para encontrar un secretario socialista adjunto en la Camera del 
Lavoro [Cámara del Trabajo] tuvieron que repescar a un viejo camarada que ya había estado allí antes de la guerra. La parte más filo-comunista se fue con la escisión, pero también la más proletaria y popular... La parte proletaria abandonó; la parte burguesa iluminada se quedó en minoría... Se abrieron huecos que poco a poco se fueron rellenando con gente procedente del PSDI [Partido Socialdemócrata Italiano]. Con estetrasvasey la ruptura, cambiaron mucho los métodos. (Entrevista F17).

En ambas ciudades, la debilidad de la organización del partido coincidió con un aumento de su presencia en todos los niveles del gobierno, con el consiguiente cambio en las motivaciones de los militantes y de los dirigentes. Si en la etapa inmediata a la posguerra el PSI había reclutado militantes de las filas de los partisanos, en el decenio de 1970 sus funcionarios procedían de la clase media. En el mismo momento en que los recursos materiales se estaban convirtiendo en los principales recursos que se repartían en el partido, la base de poder de los dirigentes tendía a desplazarse fuera del partido. En aquel tiempo la influencia dentro del partido dependía de los puestos ocupados en los organismos locales o en el Parlamento. Para obtener estos puestos era necesario promover un electorado ad personam, sobre todo entre los grupos sociales en expansión como las nuevas clases medias. En los decenios de 1960 y 1970, grupos sociales «emergentes» fueron atraídos hacia el partido. Tanto en Savona como en Florencia la creciente importancia de la industria de la construcción propició el desarrollo de unas relaciones privilegiadas entre funcionarios socialistas y grupos «emergentes» como propietarios de terrenos edificables, empresarios de la industria de la construcción, arquitectos e ingenieros. El poder de atracción ejercido por el PSI sobre estos grupos parece haber sido la disponibilidad de cargos en el gobierno local, que había aumentado enormemente, sobre todo mediado el decenio de 1970.

El relevo generacional hizo que el poder adquirido localmente fuera ejercido por un nuevo grupo dirigente. La clase política de antes de la guerra, que había mantenido su poder en el partido por medio de recursos políticos tradicionales como el carisma que suponía haber participado en la Resistencia, fue sustituida por una nueva clase política socialista formada a la sombra de las primeras experiencias de gobierno. En las entrevistas, muchos de estos nuevos dirigentes son descritos como «jóvenes turcos», «políticos rampantes», «gente de pocos escrúpulos», «personas con ánimo de enriquecimiento personal», 0 «con afán de poder en su propio beneficio» 0 «profesionales ambiciosos atraídos por la posibilidad de aliarse con quien estuviera en el poder, al margen de sus ideas o programas».

Esta nueva clase política consolidó su poder ocupando cargos de designación política en el sector público, cargos que permitían a los políticos de negocios organizar sus carreras en torno a la apropiación privada de recursos públicos. Los políticos de ne gocios, de hecho, se enriquecieron personalmente por medio de sobornos y de la explotación de su poder político en otras actividades, sobre todo en las que ese poder les hacía estar en superioridad de condiciones respecto a sus competidores. En primer lugar, las relaciones políticas hicieron posible el acceso a puestos burocráticos del sector público. Si bien estos puestos eran muy productivos en cuanto a ganancias ilegales, también las relaciones que se crearon en los mercados ilegales proporcionaron ventajas en actividades legales. Así, una carrera política se convierte en extremadamente atractiva para profesionales - médicos, inspectores- que pensaban obtener el máximo beneficio teniendo el control del proceso de adopción de medidas en el ámbito público. Por poner un solo ejemplo, los administradores ligures implicados en un caso de corrupción política en el decenio de 1980 se habían especializado en actividades especulativas en el sector de la construcción, realizando importantes inversiones inmobiliarias personales por medio de una persona interpuesta 0 a través de sociedades (Tribunal de Savona, 1984, 217).

Además, el dinero adquirido de esta forma se reinvertía en política, constituyendo un recurso suplementario para políticos corruptos rivales dentro del partido. Como explicó minuciosamente a los jueces ${ }^{7}$ el primer político implicado en la investigación milanesa $M$ ani pulite [M anos limpias]: «Fundamentalmente para comprender por qué me impliqué personalmente en el sistema de la corrupción, hay que comprender antes que yo no era Presidente de un organismo como el Trivulzio simplemente porque fuera un buen técnico, un buen gestor sanitario, sino también porque de alguna manera era un poder, alguien que controlaba un determinado número de votos en M ilán. Para adquirir ese poder, siete mil votos en total, tuve que hacer ciertos desembolsos para la creación y mantenimiento de una organización de recogida de votos en toda la región de M ilán» (CHIESA, 1992, 18, el énfasis es añadido). Por todo esto, la política resulta transformada por los recursos movilizados en los mercados ilegales. Si la crisis de organización de los partidos de masas favoreció la emergencia de una clase política para la cual los costes morales de la corrupción eran bajos, la presencia de esta clase política conduciría a la transformación de la política, de las características mismas de la rivalidad política, llevando a privilegiar nuevos recursos y capacidades.

\section{Homines novi, socialización en la corrupción y carreras políticas}

La «calidad moral» y la propensión a la corrupción no parece pues proceder directamente de la clase social. O tras explicaciones más dinámicas se han fijado en la influencia sobre el sistema normativo de la emergencia de nuevos grupos sociales y en particular, de los homines novi cuya entrada en la política, desde la 
república romana en adelante, significó el más alto grado de tolerancia hacia la desviación de las normas establecidas. Según BAN FIELD y WILSON, la mayor propensión de los recién llegados a implicarse en la corrupción política podría explicarse por la ne cesidad de los nuevos empresarios y jefes políticos de penetrar en un mundo quetiende a excluirlos. Una vez «llegados», estos mismos grupos sociales se convertirían en defensores del nuevo orden. En Estados Unidos, por ejemplo, los hombres de negocios que se hicieron ricos gracias a la corrupción, abrazarían el camino de la reforma para evitar que otros compitieran con ellos empleando las mismas técnicas. Así, según BANFIELD y WILSON:

El soborno completo de los funcionarios del gobierno local por parte de los dirigentes de empresas grandes y bien establecidas es ciertamente algo muy poco frecuente hoy. Los únicos hombres de negocios que tratarían de comprar favores del gobierno local hoy en día son los jefes de los sindicatos del crimen (del juego organizado, por ejemplo), y quizá de las nuevas empresas que tratan de penetrar en un campo ya establecido. Estos últimos - hombres de negocios «en formación»- son vistos con pena y asco (por supuesto como debe ser) por los propietarios y gerentes de empresas que se crearon exactamente de la misma manera no hace muchos años.

H oy, el hombredenegocios respetable (establecido) probablemente empleará la influencia política con fines privados solamente en lo que se podrían llamar actuaciones defensivas». Podría intentar hacer lo que fuera para evitar algunaalteración en el statu quo que afectaranegativamente a su empresa pero no es nada probable que intente perturbar el statu quo para obtener alguna ventaja para sí mismo» (BANFIELD y WILSON, 1967, 266).

Adoptando en parte estas hipótesis, Alessandro Pizzo rno ha sugerido recientemente que los homines novi son más susceptibles de participar en la corrupción porque el desarraigo que conlleva su entrada en política respecto a los anteriores grupos de referencia rebaja los costes morales de la conducta ilegal. Según el sociólogo italiano, «los 'hombres nuevos' al entrar en política tienden a romper con lo que todavía les ataba a sus raíces, 0 , dejando las metáforas, a despegarse de los grupos de referencia dentro de los cuales se habían socializado. Por el contrario, los políticos que pertenecen a las clases socialmente dominantes y por lo tanto se han socializado en grupos de referencia cuya moralidad es la misma que la de la autoridad legal, siguen considerando que sus actos se pueden juzgar y considerar de acuerdo con los criterios de esos grupos y por lo tanto, de acuerdo con sus normas» (PIZZORNo, 1992, 45). Las compensaciones monetarias ganadas por medio de la corrupción, de hecho, se pueden disfrutar de manera socialmente satisfactoria sólo si esto no conlleva la estigmatización de los grupos de referencia. Si la «desocialización» conduce a una mayor disposición a la corrupción, hay que añadir que el entorno en el que el individuo se «resocializa» tam- bién desempeña una función importante en dicha disposición a la ilegalidad.

A este respecto, nuestro estudio sobre Italia demuestra que los partidos políticos, una vez contaminados por la corrupción, se convierten en agencias de socialización en la ilegalidad; se empie zan a premiar unas ciertas capacidades más que otras. En general, los políticos de negocios no tienen ni preparación profesional ni formación ideológica que les permita cumplir las tareas requeridas por la administración pública, ni tampoco una identidad colectiva formada por medio de una comunidad de intereses, típica de los partidos de masas. Los administradores del sector público, nombrados por el partido, consideran su puesto como una compensación por la fidelidad a un líder político determinado y como un medio de incrementar sus propios recursos económicos o los de su jefe político. Esto fue bien ilustrado por uno de los políticos implicados en las investigaciones de Milán, que dijo a los jueces: «Cuando el PSI me nombró director de la ECA todo el mundo me dijo que otros se habían forrado allí aunque el sueldo era de sólo 280.000 liras al mes... Cuando me animaban a aceptar el puesto, sabían muy bien las ventajas que lo acompañaban: no sólo el coche y la secretaria sino la posibilidad concreta de «ndependizarseis o de «ahorrar para la vejez» (en N ASCIMBENI y Pam parana, 1992, 159, énfasis añadido). De hecho, el mismo administrador describió sus primeras experiencias como presidentedeun organismo benéfico, en lossiguientestérminos: «Llegó el momento de hacer el primer contrato y pregunté cómo funcionaban las cosas. M edijeron que habría una comisión y que los aspirantes concursantes tenían que estirarse hasta una cierta cantidad, equivalente a la media de las ofertas. Yo no sabía exactamente cómo funcionaba eso, pero adiviné que algo pasaría y que alguien me lo agradecería con dinero» (en CARLUCCI, 1992, 122, énfasis añadido).

Los políticos de negocios, como no tienen aptitudes especiales para ello, suelen mostrar escasa predisposición hacia la ideología e intervienen poco en la política visible. Por el contrario, se especializan en «actuar en la sombra»y dedican la mayor parte de su tiempo a las actividades ilegales: establecer contactos con los empresarios, pedir la cantidad, negociar, y recibir los sobornos. A propósito de esto, la descripción de las actividades del presidente del Pio Albergo Trivulzio (PAT) es reveladora: «os pagos,» escribió un empresario en su memorándum a los jueces, «se hacían siempre en efectivo y con frecuencia tenían lugar en el despacho [del administrador]. Acostumbraba a bajar la cortinilla para impe dir que al guien viera lo que estaba pasando. Inmediatamente metía el dinero en un sobre que dejaba al pie de su mesa. Era muy metódico y ponía un post-it en cada fajo, indicando la cantidad. Q uería que el dinero estuviera bien ordenado y se enfadaba si se le entregaba todo revuelto» (en CARLUCCI, 1992, 31, énfasis añadido).

Además de la confidencialidad, las actividades ilegales requie ren el conocimiento de las «reglas del juego». Como recordaba 
un administrador que había tomado parte en dicho «juego»: «N ormalmente la gente cree que la corrupción es sólo cuestión de dinero, que pasa de un bolsillo a otro, una cosa fácil, sin complicación, como un vulgar robo. En la práctica, no es así. Es realmente difícil explicar cómo funciona el mundo de la corrupción. Se necesita mucha paciencia para comprender sus diferentes (y casi siempre complejos) mecanismos. No es como una cadena de robos: existen reglas y relaciones, convenciones fijas, todo un lenguaje de matices y entonaciones que revisten toda la solemnidad de un contrato escrito» (LICANDRO y V ARAN 0, 1993, 18, énfasis añadido). Una jerga especial, sólo para iniciados, permite comunicar las peticiones o las extorsiones y al mismo tiempo evita el peligro de ir uno mismo demasiado lejos. En la práctica, aun cuando la corrupción sea la norma, jamás se menciona abiertamente. La aproximación inicial se hace con frases estereotipadas: "¿Así que no hay nada para nosotros?» 0 «A propósito de las necesidades del partido, como es costumbre que las empresas contribuyan a cubrirlas...» (del testimonio de un empresario en la Procura de la República de Milán 1983, 119). Baste como ejemplo la siguiente descripción realizada por un empresario que se dirigió a un representante socialista del consejo de administración de una empresa pública, solicitando trabajo para su empresa: «Trataba de demostrar las avanzadas técnicas que empleaba la empresa que yo representaba. Inmediatamente noté que [él] se estaba poniendo impaciente e irritable. Al cabo de unos minutos me dio a entender lo que quería con frases del tipo de 'ya he pasado los recados para poder proporcionar material móvil rodante, pero hay que seguir unas normas..'. 'Resumiendo, me hizo comprender que si queríamos los contratos teníamos que pagar el $5 \%$ de su valor, en concepto de comisiones (en Panorama del 5 de julio de 1992, énfasis añadido). En la fase de negociar la cantidad, se emplea todo un amplio repertorio de términos: «reembolso de los gastos», «compensación», «premio», por parte de los funcionarios públicos; «desembolsos», «gastos políticos», «costes adicionales», «obligaciones», «la norma del tanto por ciento», «gastos sin especificar», por parte de los empresarios. En la corrupción, como en los demás mercados ilícitos, es igualmente necesario el conocimiento de las técnicas empleadas para reducir al mínimo el riesgo de denuncia. Para citar sólo un ejemplo, el ex-alcalde de Reggio-Calabria describió la «profesionalidad» necesaria para preparar el dinero de los sobornos, en los siguientes términos:

Abrí el bolso y secayeron losfajos debilletes de 100.000 liras. Todo estaba perfectamente preparado y yo debía saberlo, puesto que había trabajado en un banco; todo en billetes usados, pero no demasiado estropeados. Billetes que nunca nadie podría reconocer; hubiera sido imposible seguirles la pista. Un trabajo de expertos. El quelo hubiera hecho era un especialista; sabían realmente lo que hacían. Lasbandasque envolvían el dinero eran tan anónimas como los sobres y el maletín. Nadie podría nunca probar nada. Todo el asunto denotaba solidez de organización, eficien- cia, astucia y profesionalidad. Me dije a mí mismo: «Esta gente se dedica sólo a esto» (LICAN DRO y Varano, 1993, 33).

Si bien la corrupción requiere discreción, los políticos de ne gocios, no obstante, tienen el mismo interés que otros actores de los mercados ilegales en adquirir un fama semi-pública de arrogancia. Las descripciones de los administradores corruptos hacen hincapié en sus exhibiciones de conducta agresiva y amenazante. Por poner uno de los muchos ejemplos posibles, un empresario recogió de un administrador socialista milanés la siguiente descripción: «él no consentía el menor retraso. Recuerdo que a menudo me insultaba porque me retrasaba unos días en entregar el dinero exigido. M ás de una vez... me acusó a voces, de forma que las secretarias podían oírlo, de ser un 'holgazán' un 'inútil total' y me amenazó con echarme a patadas si no hacía lo que él quería (en N ascim ben I y Pam parana, 1992, 86-7). Aunque a primera vista parezca que aumenta el riesgo de denuncias, en al gunos aspectos de la organización de la corrupción resulta muy útil tener fama de arrogante. Tener fama de «duro» 0 «autoritario» y de tomar decisiones arbitrarias aumenta entre los empresarios la sensación de los riesgos que comportaría el resistirse a las demandas de los funcionarios corruptos. La prepotencia da la impresión de un poder tan absoluto como arbitrario es su ejercicio, aumentando el temor del empresario pues le induce a creer que «un simple cambio de humor [por su parte] sería suficiente para hacerme perder el trabajo» (Ibid., 85). D e hecho, la arrogancia da la sensación de tener más poder del que se tiene en realidad y eso permite ampliar la red de contactos y la extensión del poder real. Así se completa lo que Pizzorno (1992, 25-26) ha llamado «círculo vicioso de la arrogancia»: El alarde de la capacidad de ser arbitrario crea una fama de poderoso y esto acumula la demanda de favores y crea un apoyo que se puede emplear en el terreno político para incrementar el poder real.

M ás aún, la socialización en la corrupción política induce a la interiorización de una escala de valores semejante sólo en apariencia al sistema de valores que regula la actividad legal. Especialmente, los políticos de negocios insisten en el valor de la amistad, entendida de manera interesada como una relación basada en el intercambio de favores. D e hecho, estas redes de relaciones crean la posibilidad de organizar y concluir con éxito transacciones ilegales y, a la vez, de protegerse ante la amenaza de una de nuncia y de recoger el apoyo electoral necesario para su propia carrera y para mantener el sistema de partidos. Los políticos de negocios tienen que ser también pragmáticos a la hora de distribuir los fondos dentro de su partido y más en general, dentro del sistema de partidos, para ampliar el círculo de connivencia. Por último, si bien tienen que construirse una «reputación» favorable en el mercado de la corrupción, también tienen que atenerse a un concepto particular de honradez: respetar las obligaciones asumidas en las transacciones ilegales; obligaciones no sujetas, naturalmente, a ratificación legal y cuya violación no podría ser castiga- 
da legalmente. La importancia de este sentido de la «honradez» se ve claramente, por ejemplo, en la siguiente descripción del secretario administrativo nacional del PSI: «un hombre de honor que atendía personalmente su obligaciones y, por lo tanto, por razones de seriedad y prestigio personal, entregaba en persona el dinero debido a las secciones localess) (Cámara de los Diputados, n. 202-bis, 23 de febrero de 1993, p. 12).

Resumiendo, el auge de la corrupción hace necesaria la llegada de una clase política que ha interiorizado un conjunto de normas de conducta especiales. Como he intentado demostrar otras veces (D ELLA PORTA, 1995), los partidos políticos son agentes de socialización en la ilegalidad. El partido «coloca» a sus hombres en puestos de responsabilidad de organismos públicos. Pero a cambio insiste en que cumplan las «reglas» de uso de estos cargos para la «financiación política», mientras que al mismo tiempo permite vislumbrar la posibilidad de un enriquecimiento personal. Un parlamentario socialista, presidente de un organismo público, explicaba a los jueces: «Sabía y todavía sé que los puestos clave en determinados organismos (entre ellos el IN AD EL) están ocupados por personas en las que el partido confía en que asumirán la responsabilidad de obtener aportaciones para el propio partido; en cualquier caso, sabía que cualquier cambio de mentalidad por mi parte me llevaría inmediatamentea la marginación y a la pérdida de mi pueto» (en «Tangentopoli. Le carte che scottano», suplemento de Panorama 1993, 76, énfasis añadido). El hecho de que los partidos asuman esta función permite que se extienda el sistema de los tratos ocultos. Los políticos ya «nntroducidos» en las reglas del mercado ilegal introducen a su vez a otros. La fidelidad al partido sirve para obtener puestos que más tarde se pagan con el reparto del dinero adquirido gracias a la corrupción. Un consejero regional lombardo reveló: «A portar dinero al partido era una manera de subir, de ganar la confianza de los jefes. Y mi jefe no era un cualquiera... A su lado, yo habría hecho una brillante carrera (Panorama, 12 de julio de 1992, p. 54).

\section{Las funciones de los políticos de negocios en los tratos corruptos}

D e todo lo dicho se deduce que el funcionamiento de los partidos políticos también se ha transformado por la presencia de la corrupción. En las democracias liberales, los partidos son los intermediarios entre la sociedad y el gobierno descubriendo, aunando y seleccionando intereses. La difusión de la corrupción política cambia el modo de cumplir esta función. Como PIzzorno ha observado:

Si una persona cree que la tarea de la mediación en una democracia consiste en el descubrimiento e interpretación de las necesidades y deseos de la población, la selección y generalización de los que se pueden expresar políticamente, la proposición, justificación y crítica de políticas y medidas para lograr esos fines (0, en algunos casos la explicación depor quéno se pueden satisfacer al gunas demandas), es probable que esta persona se sienta motivada para emprender esas actividades y el trabajo político por el reconocimiento público y las compensaciones que recibirán... Las aptitudes que aseguran el éxito en esas actividades pueden ser de varios tipos, pero esencialmente se resumen en una capacidad de generalizar las demandas particulares en términos ideológicos o programáticos, de manera que obtengan, dentro de ciertos límites, el mayor consenso posible... Ahora consideremos las funciones de los intermediarios políticos en un sistema corrupto: lo más probable es que, antes que nada, se encarguen de descubrir las propuestas administrativas y legislativas potencialmente provechosas; de sugerir y provocar los tratos ilegales necesarios, de localizar aquellos en los que sea posible involucrarse y, por último, de establecer los contactos necesarios entre administradores, políticos y actores privados (PIZZORNo, 1992, 22-23).

Como muestra el caso italiano, sin embargo los políticos de negocios deben obtener consenso en torno a sí mismos y en torno al sistema de partidos. En una situación de corrupción generalizada, los políticos de negocios tien en que ser capaces de hacer dos cosas: deben coordinar las actividades necesarias para el unegocio», dentro del círculo de la corrupción; fuera de éste, tienen que movilizar la ayuda a través de unos canales muy especiales (y a menudo ocultos). En relación a esto, cabe distinguir dos tipos de políticos de negocios: «cajeros del partido», especializados en la coordinación de las operaciones inherentes a la corrupción; y «jefes del sector público», expertos movilizadores del apoyo espe cial que requiere el sistema de corrupción.

\section{Coordinación de tratos corruptos: los «cajeros del partido»}

Los denominados por la prensa «cajeros del partido» en los recientes escándalos desempeñan una función fundamental en la organización del negocio de la corrupción. Aunque pueden ser secretarios administrativos del partido, es más frecuente que ocupen puestos más «informales», reconocidos solamente dentro de 
unas estructuras organizativas invisibles que existen dentro del partido. Sus carreras se basan en la confianza que el partido tiene en su capacidad de traer aportaciones, legales o no, y de gestionarlas de manera «honrada»y «digna de confianza». Estos individuos fueron descritos en los siguientes términos a los jueces de M ilán: «C ada partido tiene sus informadores encargados de controlar la asignación de contratos, de mantener los contactos con las distintas empresas, de cobrar o hacer que se cobren las comisiones. También tratan de colocar a políticos de su confianza en los consejos de administración de diferentes empresas, que después tratan directamente con los hombres de negocios... [y así] tapan lo que en realidad son tratos corruptos arreglados de antemano, con acuerdos formalmente legales» (Panorama, 12 de julio de 1992, p. 27).

La función de los cajeros en la práctica es organizar la financiación legal e ilegal de su partido. Al hacer esto, tienen que mediar entre una pluralidad de redes (y coordinarlas) compuestas por diferentes tipos de actores. Refiriéndose a un cajero demócrata-cristiano milanés, los jueces observaron: «Presidente de la compañía municipal de transportes y secretario regional administrativo de la DC, gestionaba como en una verdadera organización administrativa, el dinero que los empresarios pagaban por la adjudicación de contratos públicos. Este dinero servía para cubrir los enormes gastos de la D emocracia C ristiana y de sus líderes. Era muy conocido en los círculos políticos, y sobre todo dentro de la D emocracia C ristiana, como un «recaudador» de fondos ilegales. Fondos que después repartía para los fines antes indicados» (Cámara de los Diputados, n. 184, 8 de febrero de 1993, p. 5). En el nivel municipal, estos cajeros coordinan las actividades de los administradores del sector público pertenecientes a su partido y también son ellos los que, por estar en contacto con el cajero nacional del partido, mantienen el contacto entre el centro y la periferia. Es más, su función traspasa las fronteras de su propio partido, ocupándose de la mediación entre los diferentes partidos involucrados en el sistema de la corrupción. Según un «cajero» socialista:" «cada informador del partido rinde cuentas al secretario administrativo nacional, que prepara los balances provisionales y finales de los ingresos, y trabaja con los secretarios adminisrativos de otros partidos para controlar el flujo de fondos ilegales. Todo esto les era comunicado a los secretarios políticos de los partidos, por la razón obvia de que la actividad del partido tenía que organizarse de acuerdo con los recursos disponibles» (Camera dei Deputati, n. 166-quater, 13 de enero de 1993, p. 47). Los cajeros de los diferentes partidos coordinan la tarea de recaudación entre ellos mismos, ahorrando la energía que cada partido debe invertir en los tratos corruptos. Especialmente los «cajeros municipales» actuaban en estrecha colaboración mutua, turnándose en las tareas de solicitar y recaudar el dinero de los sobornos para todos los partidos y redistribuirlos a continuación según unas precisas (pero no escritas) reglas (ver DELLA PORTA, 1993). En las estructuras transversales de recaudación y distribución de los fondos ilegales, los representantes de los partidos se turnaban incluso en las funciones de cajero y redistribuidor. En total acuerdo asociativo, los «cajeros» de un partido, si se daba el caso, llevaban a cabo sus actividades en la sede de otro o se reunían para repartir el dinero recaudado de los sobornos. Así surgió la figura del «cajero colectivo». Los «cajeros nacionales» también se reunían para «establecer, de común acuerdo, las mejores estrategias para obtener las aportaciones de las empresas, aunque esto constituía violación de la ley de financiación de los partidos» (Cámara de Diputados, n. 210, 5 de marzo de 1993, p. 10).

Además de coordinar las actividades de los diferentes actores del sector público implicados en la corrupción, el sistema de cajeros reduce la cantidad de información comprometedora en circulación. De hecho, son los cajeros los que mantienen relación con todos los que gravitan en la órbita de los partidos políticos en busca de favores, sobre todo con los empresarios que operan en el sector público. Aunque no de manera oficial, mantienen una postura que es bien conocida por los empresarios, los cuales se dirigen a los cajeros para resolver dificultades técnicas o de tipo burocrático referentes a los contratos públicos. Como explica un cajero del PSI de M ilán, cuando se entregaba el producto de los sobornos a los «informadores» políticos ni se daban ni se pedían explicaciones: «C uando entregaba el dinero... yo no decía nada y nadie preguntaba nada. El secreto total era una práctica establecida... N o se decía a la persona que recibía el dinero de dónde procedía éste; de todas formas, normalmente es obvio ya que en un sistema de colaboración general, todos saben aunque finjan no saber» (CARLUCCI, 1992, 60-61). Esto fue confirmado por el cajero de la DC de la misma ciudad: «N unca dijea los que recibían el dinero de dónde procedía. N i ellos me preguntaban ni yo decía nada... Los pagos se hacían siempre en metálico y cada cual hacía su parte sin hacer preguntas embarazosas» (Camera dei Deiputati, n. 83, 31 de julio de 1992, p.7). Naturalmente, esta «confidencialidad» en lo referente a la procedencia y distribución del dinero de los sobornos aumentaba el poder de los cajeros, que muchas veces eran los únicos que conocían detalladamente los mecanismos y normas que regulaban su reparto.

\section{Boses del sector público y movilización del voto}

El nombramiento de cargos en los consejos de administración de las empresas públicas de Italia ha estado caracterizado por la afiliación política de los mismos. Aunque teóricamente estas decisiones dependían de asambleas electorales, que debe rían elegir personal debidamente cualificado, en la práctica, el sistema de corrupción asegura que estos cargos son designados 
por los secretarios de los partidos políticos entre miembros de la clase política. El control de la administración de las empresas públicas constituye por esto un recurso de primer orden en la carrera de muchos políticos; éstos se podrían definir, tomando prestado un término empleado por los sociólogos americanos desde el decenio de 1930, como boss de las empresas públicas ${ }^{8}$. Como los bosses tradicionales de las máquinarias de partido ame ricanas, estos políticos compran apoyo por medio de un empleo patrimonial de los recursos públicos. Sin embargo, a diferencia de sus colegas americanos, que tenían que hacer frente a la falta de servicios sociales con fondos de sus propios bolsillos, estos modernos bosses pueden contar con los abundantes recursos de un estado de bienestar bien desarrollado. Como sus antiguos equivalentes, los bosses de las empresas públicas cumplen una función necesaria en el sistema político: la movilización del apoyo electoral.

A lo largo de este estudio, quedó claro en primer lugar, que estos bosses del sector público creaban unas relaciones privilegiadas con ciertos grupos de empresarios, escogidos para financiar a la vez su propia carrera y, naturalmente, el sistema de partidos. Según un administrador milanés, convicto de cargos de corrupción, ante la importante disminución de las fuentes de autofinanciación, los costos de la organización del partido cada vez más elevados, se pagaban gracias a los tratos con empresarios particulares: «Algunos sectores económicos, sobre todo los relacionados con la construcción, están unidos en una especie de simbiosis con las autoridades públicas para asegurar la continuidad de su negocio. Como es bien sabido, a cambio, pagan sobornos» («Tangentopoli. Le carte che scottano», suplemento de Panorama 1993, 23). El caso de un «arribista» director de una empresa funeraria, descrito como alguien que ha pasado de llevar una maleta de cartón a un coche de carreras (AND REOLI, 1993, 22) ilustra a la perfección esta simbiosis. A propósito de él observó un administrador milanés: 'Se convirtió en un aliado natural y estaba encantado con mi ascendente carrera política. Insistió en hacer al arde de su contacto [conmigo] y de ayudar [me] en todo, incluso cuando esto significaba pagar de su propio bolsillo. 0 bligaba a sus empleados a apuntarse a mi sección del partido, llenaba de claveles los salones para asambleas del partido y pagaba las cenas electorales》 (en ANDREOLI, 1993, 22). Como se ve en estos ejemplos, los sobornos y el apoyo electoral no se excluyen mutuamente. Para un empresario que se encuentra en una situación de mercado ventajosa gracias al pago de sobornos, podría ser interesante crear una relación estable con su oponente político y así votar y hacer votar por la persona con la que mantiene tratos corruptos. La corrupción puede así convertirse en un medio de crear apoyo electoral incluso entre aquellos a quienes se les piden comisiones y, a la vez, se les hace pensar que necesitan un protector poderoso.

El deseo de aumentar la circulación de dinero procedente de los sobornos es lo que induce a los políticos corruptos a multipli- car las actividades y los gastos de las empresas que controlan. Haciendo esto multiplican las oportunidades de hacer favores con los cuales aumentan su apoyo por partedel «respetable» como dijo un entrevistado. Para aumentar el volumen de los sobornos, tienen que gastar más dinero público, sobre todo en los sectores en los que las ganancias ilegales parecen mayores. Algunos políticos implicados en recientes investigaciones de corrupción hacen hincapié en su imagen «dinámica», una autorrepresentación que sirve también para facilitar su participación ya que ofrece una justificación «moral» de la corrupción. La descripción de un eminente colega por un administrador de C alabria hace hincapié en esto amablemente: Él está realmente convencido de haber perse guido siempre el interés general con abnegación y espíritu de servicio. Tenía una teoría. Reggio estaba en competencia con otras ciudades, Calabria con otras regiones. Asegurar inversiones, aun por medio de estos procedimientos, servía a los intereses de la población y contribuía a la prosperidad de la ciudad. París bien vale una misa, y las obras públicas bien valían un pequeño cohe cho, aunque haciendo eso, el sistema se perpetuara. D ecía: «Éste es el único camino: Si no, no hay obras públicas, no hay trabajo, no hay ayuda para los pobress (LICAND RO y VARANo, 1993, 71).

Además, las descripciones que se hacen de los bosses del sector público suelen subrayar su «poder de corromper»: la capacidad de conceder favores a un gran número de individuos privilegiando a los sectores y grupos que ofrecían mayores «compensacioness en términos de apoyo y connivencia. U na estrategia de crear connivencia entre los actores encargados de vigilar la actuación de la administración pública, se explicó de la siguiente manera por el antes mencionado ex-alcalde de Reggio-Calabria: «En una palabra, yo pagaba a todo el mundo: a los políticos, a los honrados funcionarios del Estado que tenían que controlar la corrección de mis decisiones administrativas, incluso a un juez de la Audiencia N acional. Y naturalmente, pagaba al periodista considerado más influyente de la ciudad cuyos artículos ponían firmes tanto al partido de la mayoría como al de la oposición y manejaba a muchos magistrados influyentes del Palacio de Justicia (LICANDRO y Varano, 1993, 3).

Estos bosses construían también redes de apoyo entre los empleados de las empresas que gestionaban. El aumento de personal junto con un empleo descarado de todas y cada una de las leyes que permitían esquivar la exigencia de imparcialidad en la contratación, hacían posible crear un entorno de fieles vasallos. Las empresas en las que la corrupción estaba más extendida eran también aquellas en las que las prácticas de contratación clientelista eran más comunes, a menudo en favor de los activistas del partido. Tomando sólo dos ejemplos: según los testigos, la M etropolitana M ilanese se empleaba como una reserva de afiliaciones políticas, compañeros que cobraban un sueldo de la M M sin siquiera hacer acto de presencia» (ANDREOLI, 1993, 51), mientras en la sociedad del aeropuerto «todos los contratados lo eran por razones políticas: alcaldes, asesores y consejeros de zonas alejadas, y 
también dirigentes del partido con miras a obtener el apoyo de sus seguidores» (en ANDREOLI, 1993, 132).

Por último, el dinero de los sobornos ofrece mayores oportunidades para crear un amplia clientela electoral de manera que permitiera una organización más efectiva de la máquinaria política de los bosses. Como explicó un administrador convicto de corrupción: «iQ ue una enfermera quería que se contratara a su hijo ...? Estupendo, eso está hecho. ¿Q ue un compañero necesitaba un alojamiento porque le habían echado? Estupendo, trataremos de encontrarle un apartamento en una vivienda municipal. ¿Q ue un médico del hospital quería cambiarse de un servicio a otro? D e acuerdo, presionaremos a la administración del hospital. Así me hice muy popular. Años más tarde, cuando me encontré con un compañero, tuve el placer de ver que todavía llevaba en su cartera el santino, la tarjeta con mi nombre, que repartimos por miles en campaña electoral» (AND REOLI, 1993, 42-43). La gestión de las empresas públicas también permitía crear relaciones corruptas con al gunas categorías profesionales, que a menudo tenían una capacidad autónoma de construir clientela electoral. Los médicos son un ejemplo típico. Como recuerda el administrador de un hospital milanés: «En la calle C astelfidardo me reunía con los jefes de servicio reales o aspirantes, que buscaban mi apoyo para lograr la promoción o para obtener un traslado» (en ANDREOLI, 1993, 31). Esta protección política se puede pagar en metálico: «En el hospital Fatebenefratelli regía un sistema de sobornos. Un puesto de jefe de servicio podía costar unos 100 millones [de liras], pagados por el partido interesado a la persona adecuada (ANDREOLI, 1993, 31). O pcionalmente, se podía pagar en clientes: «No hay un jefe de servicio de hospital que no haya hecho una profesión de credo político más o menos públicamente; incluso médicos de gran valía. Los méritos cuentan muy poco en el escalafón. Se sube si se tienen contactos en el partido. Llegas a jefe de servicio no porque seas una lumbrera en la profesión sino porque seas capaz de garantizar votos en el momento oportuno» (en AN DREOLI, 1993, 84, énfasis añadido). Si los cajeros, coordinando los tratos ilícitos, contribuyen a la difusión de la corrupción, los bosses del sector público movilizan unos apoyos muy especiales para el sistema corrupto, construyendo redes de clientes y protectores.

\section{La carrera política en el sector público y la corrupción: algunas conclusiones}

La difusión de la corrupción está en interacción con la emergencia de una nueva clase política, los políticos de negocios, cu- yas características hemos intentado definir aquí partiendo de un estudio sobre el caso italiano. Los políticos estudiados pertenecen ciertamente a los que, según la conocida definición de W EBER (1919), «viven de la política» persiguiendo ventajas extrínse cas o instrumentales. Son «políticos de profesión», sobre todo en una acepción del término: políticos que ven en la política un medio de subir en la escala social (M AOstropaolo, 1990, 5859). Como hemos visto en el primer apartado de este artículo, la crisis de los partidos de masas da lugar a que se suavicen las fronteras de la conducta ilegal. En esta situación, una clase política motivada principalmente por cuestiones ideológicas ha sido sustituida por individuos que consideran la política básicamente como un negocio. Contrariamente a los resultados de los estudios sobre las political machines americanas, la difusión de la corrupción no está necesariamente ligada al acceso de los «ex-plebey0s» que suplantan las clases medias. M ás bien se desarrolla cuando la política empieza a atraer principalmente a los individuos que pueden y quieren sacar provecho personal del control de los recursos públicos.

U tilizando los recursos extra, recaudados en los mercados ilegales, los políticos de negocios ocupan los partidos políticos, ganándoles la partida a sus colegas «honrados». D eesta forma, transforman por completo la manera de hacer política. Con la difusión de la corrupción se transforman también los procedimientos de hacer carrrera: los métodos tradicionales como el mérito individual, el ascenso a través de la burocracia del partido o los conocimientos técnicos específicos se sustituyen por ocultos vericuetos. En el apartado segundo vimos que los «talentos» más apropiados para organizar la corrupción son los que se premian en el ámbito de la política oculta. En efecto, los políticos de negocios poseen la capacidad de ilegalidad, definida por PIzzo Rn o en los siguientes términos (1992, 23): «Para los que la poseen [esa capacidad] es una cuestión de poder actuar bajo la constante amenaza de ser descubiertos y castigados, de burlar la vigilancia, de saber tapar sus huellas y protegerse. Y lo que es más importante aún, tienen que tener el más amplio y directo conocimiento posible de los individuos, tanto de los que desean participar en la corrupción como de los que, aunque no deseen involucrarse, ocupan altos cargos en las áreas en las que más abundan las oportunidades». Como hemos visto, los actores que se mueven en el sistema de la corrupción han creado y contribuido a difundir un conjunto de reglas que, junto a una jerga reservada a los iniciados, permite que la corrupción se lleve a cabo con el mínimo de riesgos de «duplicidad» dentro del sistema, y de denuncias fuera de él. En estas circunstancias, los partidos políticos contaminados por la corrupción socializan a sus administradores en estas actividades. En efecto, se transformaban precisamente las normas del grupo que debería inducir a respetar las normas sociales dominantes. Si la obligación moral de adaptarse a los valores establecidos, normalmente empuja en dirección a la legalidad, esto se trastorna por completo cuando los partidos políticos se convierten en lu- 
gares para la difusión de un sistema de normas que premia la conducta ilegal en lugar de condenarla.

La difusión de la corrupción requiere además el desarrollo de unas funciones específicas que cumplan diferentes cometidos. En el tercer apartado hicimos una distinción entre entre dos clases de políticos de negocios: los «cajeros del partido» y los «bosses del sector público». Los primeros se especializan en la coordinación y difusión del sistema de la corrupción. O rganizando las actividades de los administradores nombrados por partidos corruptos y de los que los apoyan, contribuyen a la imposición de la uregla del soborno» a los empresarios que trabajan en los mercados del sector público. De hecho, cualquier intento de ignorar el sistema alternativo de normas creado por la invasión de la corrupción en la adminisrración pública conlleva el riesgo de un severo castigo. Las expectativas de que el «juego» se repita y el hecho de que los partidos actúen como centros de poder ratificando los tratos, permiten que se extienda la corrupción y se castigue cualquier intento de «duplicidad» (V ANNUCCI, 1993). Los bosses del sector público, por su parte, se especializan en la movilización de apoyo. D emuestran una habilidad fuera de lo común para crear amplias redes de amigos y clientes, de protectores y protegidos, de empresarios y políticos y movilizar luego estos contactos para culminar con éxito sus «negocios». Para aumentar el volumen potencial de sobornos formulan nuevos proyectos con frenesí, pagan asesorías, compran y venden propiedades públicas y contratan servicios inútiles, alimentando aś una demanda pública poco atenta a las necesidades reales y planeada en realidad para incrementar los recursos gestionados. Todo esto permite que los negocios ilegales se lleven a cabo con éxito y que el dinero aumente, pero sirve también para crear una red personal de apoyo consistente sobre todo en clientes pero también en protectores, en la elite local. Corrupción y clientelismo parecen así reforzarse mutuamente ${ }^{9}$ pues ambos fenómenos crean un modelo de movilización individual y una concepción de la politica como un método de promoción personal. Ambos aparecen ligados a una gestión de la administración pública destinada a conceder, o más bien a inventar, «favores».

Sin embargo, como los recientes acontecimientos de Italia parecen demostrar, el tipo de apoyo obtenido a través de la corrupción y del clientelismo es incapaz de proporcionar una verdadera legitimidad al sistema político. Empleando términos de EASTON (1975), crea apoyo para los políticos de negocios a título individual pero no un apoyo general a las instituciones del gobierno. El mecanismo de la corrupción, para sobrevivir, tieneque aumentar la participación en ell a sin cesar ya que es precisamente esa participación lo que intensifica los vínculos de la connivencia. Sin embargo, esto produce una espiral inflacionista que da lugar a una reducción de los recursos materiales y simbólicos disponibles a la vez que genera descontento entre los excluidos del sistema de la corrupción. Así pues, una coyuntura económica adversa, un aumento de las expectativas y la emergencia de nuevas fuerzas políticas pueden conducir al derrumbe de los partidos y de la clase política considerados responsables de la corrupción, como ocurrió en Italia entre los años 1992 y 1994.

\section{Notas}

* Profesora de Políticas Locales en la Facultad de Ciencias Políticas de la Universidad de Florencia.

1 Se pueden encontrar antologías de escritos sobre la corrupción política en Heidenheim er, 1970; H eidenheimer, Johnston y LeVine, 1989; y Della Porta Y M ÉNY, 1994.

2 Uno de los principales estudios funcionalistas de los bosses políticos es, desde luego, el de M ERTON de 1957. El deH UnTINGTON de 1968 se considera en general como perteneciente a la misma tradición.

${ }^{3}$ El estudio sistemático más reciente que adopta esta aproximación es el de Susan RoSE-ACKERM AN 1978. Se puede encontrar un resumen muy útil de los argumentos de la political economy approach en BENSON y BADEN, 1985.

4 Sobre los políticos de negocios, ver también D elLA PORTA, 1992 y D elLa Porta y PIZZORNO, 1993.
${ }^{5}$ Paralos resultados generales del estudio, ver D ELLA Po RTA, 1992 y V AN NUCCI, 1994.

${ }^{6}$ Aquí y más adelante, se hace referencia a entrevistas de participantes en la corrupción u observadores bien informados. Para mayor información relativa a las entre vistas, ver DeLLA PORTA, 1992.

${ }^{7} \mathrm{M}$ ani pulite es el término empleado en los medios de comunicación para referirse a diferentes investigaciones sobre corrupción en la administración pública que empezaron en Milán, en febrero de 1992 y se ha extendido desde entonces hasta involucrar a cientos de políticos y empresarios, ha implicado a los líderes de los principales partidos y provocado la crisis política más profunda en la historia de la República italiana (ver D ella PoRTA y VANNUCl, 1994).

8 Por ejemplo, ZIN K 1930, y más recientemente Rogow y LASSWELL, 1963.

9 Sobre el clientelsmo político y las razones para su difusión, ver EISENSTADT y Roniger, 1984. Sobre el clientelismo en Italia, GrazIAno, 1980.

\section{Bibliografía}

AA.VV. (1993), «Tangentopoli. Le carte che scottano», suplemento de Panorama, febrero.

Andreoli, M . (1993) Andavamo in Piazza D uomo, Milán, Sperling and Kupfer.
Banfield, E.C. y J. Q. Wilson (1967), City Politics, Cambridge, Cambridge University Press.

Benson, B.L. y J. Baden (1985), «The Political Economy of Governmental 
Corruption: the Logic of Underground Government», en Journal of Legal Studies, 14, 391-410.

Camera del Deputati (1993-1994), Domande di autorizzazione a procedere in giudizio, doc. IV.

CarlucCl, A. (1992), Tangentomani, M ilán, Baldini \& Castoldi.

CHIESA, M. (1992), «Confessioni che cambiano la storia», en L'Espresso, 28 junio.

D aHL, R. (1961), Who Governs, Democracy and Power in an American City, New $\mathrm{H}$ aven, Yale University Press.

Della Porta, D. y Y. M Ény (eds.) (1994), Democratie et corruption, París, La Decouverte.

Della PorTA, D. (1992), Lo scambio occulto. Casi di corruzione politica in Italia, Bolonia, II Mulino.

Della Porta, D. (1993), «Milano. Capitale inmorale», en Politica in Italia, G. Pasquino y S. H ellman (eds.), Bolonia, II M ulino.

Della Porta, D. (1995), «Partispolitiqueset corruption», en Politix, no 30, p. 61-75.

Della PortA, D. y A. VanuCCI (1994), Corruzione politica e amministrazione pubblica: Risorse, meccanismi e attori, Bolonia, II M ulino.

EASTON , D. (1975), «A Reassessment of the Concept of Political Support», en British Journal of Political Science, 5, 435-457.

EISEN STADT, S.N . y L. RONIGER (1984), Patrons, Clients and Friends. Interpersonals Relations and the Structure of Trust in Society, Cambridge, Cambridge University Press.

Grazian 0, L. (1980), Clientelismo e sistema politico. II caso dell'Italia, Milán, Franco Angeli.

Heidenheimer, A.J. (ed.) (1970), Political Corruption: Readings in Comparative Analysis, New Brunswick, Transaction.

H eiden Heim ER, A.J., M. Johnston y V. Levine (eds.) (1989), Political Corruption. A H andbook, New Bunswick, Transaction.
H untington, S.P. (1968), Political Order in Changing Society, New Haven, Yale University Press.

Licand do, A. y A. Varano (1993), La città dolente. Confessioni di un sindaco corrotto, Turín, Einaudi.

Mastropaolo, A. (1990), II ceto politico. Teoria e pratica, Roma, La Nuova Italia Scientifica.

M erTon, R.K. (1957), Social Theory and Social Structure, Nueva York, Free Press. N ascim benI, E. y A. Pam parana (1992), Le M ani Pulite, Milán, A. M ondadori.

Pizzorno, A. (1992), «La corruzione nel sistema politico», introducción a della PORTA, D., Lo scambio occulto, Bolonia, II M ulino.

Pizzorno, A. y Della Porta, D., (1993), «G eschäftspolitiker in Italien: Überlegungen im Anschlu- eine Studie über politische Korruption», en Kölner Zeitschrift für Soziologie und Sozialpsychologie, 45, n.-0 3, pp.439-464.

Procura della Repubblica di M ilano (1983), Requisistoria del Pubblico Ministero nel Procedimento Penale n. 0 990/83.

Rose Ackerm an, S. (1978), Corruption: A Study in Political Economy, Nueva York, Academic Press.

TILMAN, R. O . (19678), «The Emergence of Black M arket Bureaucracy: Administrative Corruption in the New States», en Public Administration Review, $28,437-444$.

Tribunale di Savona (1984), Sentenza di rinvio a giudizio n.1019/81 R.G.P.M., 24 de agosto.

V AnNUCI, A. (1993), «Fenomenologia della tangente: la razionalità degli scambi occulti», en Etica degli affari e delle professioni, suplemento de L'impresa, 1/3, 30-42.

W EBER, M . (1919), Politik als Beruf, M unich and Leipzig, D uncker und H ombolt. ZIN K, H. (1930), City Bosses in the United States. A Study of Twenty M unicipal Bosses, Durham, N.C., D uke University Press. 